Macedonian Pharmaceutical Bulletin, 66 (Suppl 1) 205 - 206 (2020)

Online ISSN 1857 - 8969

UDC: 665.58:340.13(4-672EУ)

DOI: 10.33320/maced.pharm.bull.2020.66.03.102

Short communication

\title{
Satisfied customers and Good Commercial Practice challenge for the pharmacy law in the cosmetic industry
}

\author{
Katerina Ancevska Netkovska ${ }^{1}$, Jadranka Dabovikj-Anastasovska ${ }^{2}$ \\ ${ }^{I}$ Faculty of Pharmacy, Ss. Cyril and Methodius University, Mother Tereza 47, 1000 Skopje, North Macedonia \\ ${ }^{2}$ Iustinianus Primus Law Faculty, Ss. Cyril and Methodius University, bul. Goce Delchev 9b,
} 1000 Skopje, North Macedonia

\section{Background}

The Pharmaceutical Law, specifically the part of this law that provides the legal framework for cosmetic products in the EU, comprises of rules for the production, safety, distribution and marketing of cosmetic products. We asses that the legal regulation of the cosmetics industry is particularly important because: first, there is a significant expansion of the industry; second, these products are separated by a thin line from the group of products considered to be medicinal products; and third, after the food industry the cosmetics industry is the one that has the largest number of consumers in the world.

Research shows that the cosmetics industry is expanding in the EU. In our country, there are number of small and medium-sized companies in the field of production, especially of organic cosmetics. Of course, the largest producer and exporter remains Alkaloid AD Skopje.

It is considered that the vast majority of Europe's 500 million consumers use cosmetics and personal care products (hereafter 'cosmetics'). European consumers spend, on average, $€ 135$ per year purchasing different cosmetic products.

Ensuring equal rights for consumers in the common market and protecting consumers from unfair business practices at all stages of commercial relations between traders and consumers i.e. prior to the sale, during the transaction and after the sale is particularly important when it comes to consumer rights in the European Union.

In this paper we analyze the EU legal framework for cosmetic products, with purpose to answer whether this legislation provides adequate and satisfactory consumers' protection in the common market. The analysis also aims to show that specific sectoral rules, combined with horizontal consumer protection rules, can to some extent provide for the prevention of unfair business practices. Besides having a comprehensive legislation, it is certainly very important to implement this legislation in practice so as to reach the required levels of consumer protection and competitiveness. In this regard, it is to be noted that other branches of law such as Intellectual Property Law and Competition Law contribute to the achievement of the set goals.

Therefore, the comparative legal method was used to assess the level of alignment of the national legislation with the relevant EU regulation of cosmetic products.

\section{Results and discussion}

The aggressive and deceptive practices have been present mostly in the electronic trading, but research has shown a violation of the rules as to the accuracy of the claims and the rules on advertising

\footnotetext{
* kaan@ff.ukim.edu.mk
} 
in all types of sales (COM (2016) 580 final). One of the problems that are considered particularly acute in the EU is when cosmetic products are attributed with medicinal effects. Most Member States identified claims that a cosmetic product has medicinal functions or curative or biocidal effects, although the responsible person could not give evidence to support this, have the most dangerously misleading claims for consumers. Believing that a cosmetic product has therapeutic effects and medicinal properties could lead consumers to delay adequate medical treatment (Regulation (EU) No 655/2013, Guidance Document).

The Regulation (EC) No 1223/2009 on cosmetic products and Directive 2005/29/EC on business-toconsumer unfair commercial practices (UCPD) have a similar objective, to protect consumers from misleading claims, and the latter may apply in a complementary manner to cosmetic claims, to the extent these qualify as a commercial practice within the meaning of the UCPD. The provisions of the Cosmetics Regulation, as lex specialis, prevail over the UCPD where the specific aspects of unfair commercial practices are regulated by the former. That principle is clearly established in the UCPD, which provides in its Article 3.4 that in the case of conflict with 'other Community rules regulating specific aspects of unfair commercial practices' the latter shall prevail and apply to those specific aspects. That principle is further clarified in recital 10 of the UCPD which states that the 'Directive accordingly applies only in so far as there are no specific Community law provisions regulating specific aspects of unfair commercial practices, such as information requirements and rules on the way the information is presented to the consumer.

In the Republic of N. Macedonia, in the process of adoption of the new Law on Consumer Protection as a general law, and more specifically in the case of the products and services, for which there are specific departmental rules, there was a question of whether this law shall provide for the implementation of the supervision and enforcement of the rules of the general law by the competent departmental bodies, especially the unfair commercial practice, or whether they can be performed by the state market inspectorate. In the final version of the draft LCP, the standpoint that the supervision and implementation of unfair commercial practice will be performed by competent departmental bodies prevailed. In our case, regarding cosmetic products, the competent departmental body is the State Sanitary and Health Inspectorate. The afore-stated shall be valid only if the practice is unfair in relation to claims for cosmetic products. With respect to the prices or certain forms of advertising and aggressive commercial practices the responsible authority shall be the State Market Inspectorate. This separation of the supervision and enforcement responsibilities sometimes gives negative effects because, either both bodies consider themselves to be competent, or both regard themselves as not competent.

\section{Conclusion}

Further efforts should be made on national level for the approximation of the national legislation and practices. The competent authorities should have more proactive role in protection of the consumers of cosmetic products. The level of knowledge and skills of the relevant business sector should be increased so as to provide adequate services to the consumers but also to take measures against competitors who act unfairly and distort the competition.

\section{References}

Commission Regulation (EU) No 665/2013 of 10 July 2013 laying down common criteria for the justification of claims used in relation to cosmetic products, OJ L 190, 11.7.2013.

Directive 2005/29/EC of the European Parliament and of the Council of 11 May 2005 concerning unfair business-to-consumer commercial practices in the internal market, OJ L 149, 11.6.2005.

Guidance Document on the Demarcation Between the Cosmetic Products Directive 76/768 and the Medicinal Products Directive 2001/83 as Agreed Between the Commission Services and the Competent Authorities of Member States.

Report from the Commission to the European Parliament and the Council on Product Claims Made Based on Common Criteria in the Field of Cosmetics COM/2016/0580 final.

Maced. Pharm. Bull. 66 (Suppl 1) 205 - 206 (2020) 